\title{
Effect of Competitive Adsorption at the Interface between Aqueous Electrolyte and Solid Electrode
}

\author{
Kristoffersen, Henrik H.; Chang, Jin Hyun
}

Published in:

Computational Photocatalysis

Link to article, DOI:

10.1021/bk-2019-1331.ch010

Publication date:

2019

Document Version

Peer reviewed version

Link back to DTU Orbit

Citation (APA):

Kristoffersen, H. H., \& Chang, J. H. (2019). Effect of Competitive Adsorption at the Interface between Aqueous Electrolyte and Solid Electrode. In D. K., S. K., \& Y. H. (Eds.), Computational Photocatalysis: Modeling of Photophysics and Photochemistry at Interfaces (pp. 225-238). American Chemical Society. https://doi.org/10.1021/bk-2019-1331.ch010

\section{General rights}

Copyright and moral rights for the publications made accessible in the public portal are retained by the authors and/or other copyright owners and it is a condition of accessing publications that users recognise and abide by the legal requirements associated with these rights.

- Users may download and print one copy of any publication from the public portal for the purpose of private study or research.

- You may not further distribute the material or use it for any profit-making activity or commercial gain

- You may freely distribute the URL identifying the publication in the public portal 


\title{
Effect of Competitive Adsorption at the Interface Between Aqueous Electrolyte and Solid Electrode
}

\author{
Henrik H. Kristoffersen ${ }^{[1]}$, Jin Hyun Chang ${ }^{[2]}$ \\ ${ }^{1}$ Department of Physics, Technical University of Denmark, DK-2800 Kgs. \\ Lyngby, Denmark \\ ${ }^{2}$ Department of Energy Conversion and Storage, Technical University of \\ Denmark, DK-2800 Kgs. Lyngby, Denmark
}

*Tel: +45 21459488; E-mail: hhkri@dtu.dk

\begin{abstract}
At aqueous electrolyte-solid interfaces water molecules often need to be displaced to allow room for non-water adsorbates (molecules and ions) to access the solid surface. The displacement of water molecules requires an energy cost, which weakens the adsorption strength of non-water adsorbates. Such a process is referred to as competitive adsorption, and it is often overlooked in computational modeling, especially when static models are used to approximate the liquid water. $A b$ initio molecular dynamics simulations accurately describe the dynamic nature of liquid water and capture the competitive adsorption effect but require a significantly higher computational cost. We discuss how one can use molecular dynamics to study aqueous electrolyte-solid interfaces and ways in which a simple approximation can be developed to estimate the molecular dynamics simulation results. We highlight some of the interesting studies on competitive adsorption such as its dependency on electrostatic potential. There are only limited computational studies that sufficiently account for the competitive adsorption process. However, the number is expected to rise as
\end{abstract}

RESERVE THIS SPACE 


\section{Introduction}

A competition between two or more species to be adsorbed on to the surface of an adjacent solid occurs in many electrolyte-solid interfaces, and such a process is commonly referred to as competitive adsorption. One class of examples is the poisoning of electrocatalyst surfaces when the ions (especially anions) in an electrolyte ${ }^{1}$ restrict the access of reactants to the surface by outcompeting them in the adsorption process. ${ }^{2}$ For the case of aqueous electrolytes, water is usually a reference solvent, and it is sometimes overlooked that the adsorbates (ions and molecules present in the electrolyte) not only have to compete with each other but also with water molecules in order to access the surface. Therefore, water molecules in aqueous electrolytes cause competitive adsorption, when nonwater adsorbates displace adsorbed water molecules from the surface, which require an energy cost. In other words, the competitive adsorption is a destabilizing effect on non-water adsorbates that counteracts the solvation effect, which usually stabilizes ions/molecules compared to their gaseous state (although solvation does include an energy cost of cavity formation in the solvent).

In computational studies of the interfaces between the aqueous electrolyte and solid, the destabilizing competitive adsorption process is often omitted. The inclusion of competitive adsorption may lead to discoveries that were undetected in previous studies that omitted such a process. For an example of heterogeneous catalysts, the adsorption strength of reactants is known to be closely related to the activity of the catalysts. Therefore, the adsorption energy has been used as a descriptor to assess the catalytic activities of materials without extensively mapping out their full reaction energy landscapes. ${ }^{3}$ Such an accelerated approach has proven to be useful in many applications such as improving the electrochemical oxygen reduction reaction ${ }^{4}$ and understanding the catalytic activity of different metals for methane steam reforming. ${ }^{5}$ However, the inclusion of the competitive adsorption effects could shift the adsorption energies, which may reclassify the previously discarded materials as promising candidates.

We are aiming to describe the current understanding of competitive adsorption in this chapter. In Section 2, we briefly discuss how computer simulations at the atomic level can be used to capture the competitive adsorption and point out potential pitfalls of using static approximation methods. We demonstrate how the adsorbed $\mathrm{H}_{2} \mathrm{O}$ molecules on the hydrophilic surface of rutile $\mathrm{TiO}_{2}(110)$ lead to strong competitive adsorption effects in Section 3. In Section 4, we discuss subtle competitive adsorption effects on more hydrophobic metal surfaces such as $\mathrm{Cu}$ and $\mathrm{Pt}$, and the impact of electrostatic 
potential on the competitive adsorption. The summary and outlook of research on the topic of competitive adsorption are discussed in Section 5.

\section{Studying water-solid interfaces and competitive adsorption}

Much of computational work has so far been focusing on (pure) water-solid interfaces, and several reviews and perspective articles have been published on this topic recently. ${ }^{6-10}$ One of the most important recent development in the field is the employment of $a b$ initio molecular dynamics (AIMD) simulations based on density functional theory (DFT), which allows one to gain a detailed atomic insight into the dynamic structure of liquid water. Using AIMD, the structures of both liquid water-oxide interfaces ${ }^{11,12}$ and liquid water-metal interfaces ${ }^{13,14}$ have been mapped out.

The analysis of interfaces between the aqueous electrolyte and solid is more complex due to the presence of solutes, which may compete with water molecules to be adsorbed on to the surface. Competitive adsorption between solvent (i.e., water) and solute molecules (A) is naturally captured in molecular dynamics simulations where the solute and a number of solvent molecules $\left(n \mathrm{H}_{2} \mathrm{O}\right)$ can be exchanged between the surface and a liquid solvent reservoir, which is expressed as

$\mathrm{A}(\mathrm{aq})+n \mathrm{H}_{2} \mathrm{O}^{*} \leftrightarrow \mathrm{A}^{*}+n \mathrm{H}_{2} \mathrm{O}(l)$.

Molecular dynamics simulations, in principle, ensures that (i) the surface has the correct amount of surface-bound water molecules when they are in equilibrium with bulk liquid water and that (ii) any water molecule displaced from the interface moves into the bulk liquid region and assumes the energy of water molecules in bulk liquid water.

Other than the AIMD, there are two approaches to model the interface between the liquid water and solid that are widely used traditionally due to their lower computational costs. The first approach is to approximate the liquid water in contact with the surface using thin, ice-like layers of water molecules that remain static (i.e., optimized structure calculations based on DFT). ${ }^{7,15}$ Another approach is to use the so-called implicit water model ${ }^{10}$ where the water molecules are substituted by a dielectric continuum layer in order to reduce the total number of atoms in the computation cell, which in turn reduces the computational cost. These two approaches can capture the solvation effects quite well. ${ }^{16}$ However, neither of the two models inherently ensure that the surface has the correct water coverage nor that the displaced water molecules assume the energy of the water molecules in bulk liquid water; they do not necessarily capture the competitive adsorption effects.

Although employing AIMD to accurately describe the liquid-solid interfaces is a recent development in the computational domain, there are 
several established experimental techniques based on interface-sensitive spectroscopy methods which can observe the effects of competitive adsorption. Examples include Fourier-transform infrared spectroscopy (FTIR) ${ }^{17,18}$ and sumfrequency generation spectroscopy. ${ }^{19}$ One notable application example is the study on the competitive adsorption between acetic acid, methanol, and water on anatase $\mathrm{TiO}_{2}$ using sum-frequency generation spectroscopy ${ }^{20}$ - the study found that water molecules do not displace acetic acid while displacing methanol from the surface.

\section{Competitive adsorption at water-oxide interfaces}

Many frequently studied metal oxide surfaces such as $\mathrm{TiO}_{2}(110),{ }^{21} \mathrm{MgO}(100),{ }^{22}$ and $\alpha-\mathrm{Fe}_{2} \mathrm{O}_{3}(0001)^{23}$ are hydrophilic and are covered by a thin water film even at relatively low humidity. The presence of a water film under ambient conditions means that non-water adsorbates have to displace water molecules to gain access to the surface, which involves competitive adsorption between the adsorbates and water molecules. The extent to which the competitive adsorption process weakens a molecule's adsorption energy depends on the adsorption strength of the adsorbed water molecules and on how many water molecules need to be displaced to allow room for one molecule to access the surface.

Temperature programmed desorption (TPD) is a valuable experimental tool for investigating the adsorption strength of water molecules at the surfaces. TPD observes the molecules desorbing from the surface as the temperature of the surface is increased, thereby measuring the stability of adsorbates on the surface (i.e., more stable adsorbates desorb at a higher temperature while less stable adsorbates desorb at a lower temperature). Henderson and coworkers ${ }^{24}$ have shown that rutile $\mathrm{TiO}_{2}(110)$ with sub-monolayer water $\left(\mathrm{D}_{2} \mathrm{O}\right)$ coverages has a peak between 250 and $325 \mathrm{~K}$ in the TPD spectra while multiplayer coverages have an additional peak at $175 \mathrm{~K}$ (see Figure 1). The desorption temperature of the water molecules in the multilayer peak reflects the stability of a thin ice layer in a vacuum. The TPD spectra indicate that the water molecules constituting a sub-monolayer water coverage is significantly more stable than those constituting a multilayer coverage. A similar observation was made for $\mathrm{MgO}(100)$ where the TPD spectra have a peak at $230 \mathrm{~K}$ and $150 \mathrm{~K}$ when covered by a monolayer and multilayer of $\mathrm{D}_{2} \mathrm{O}$, respectively. ${ }^{25}$ 


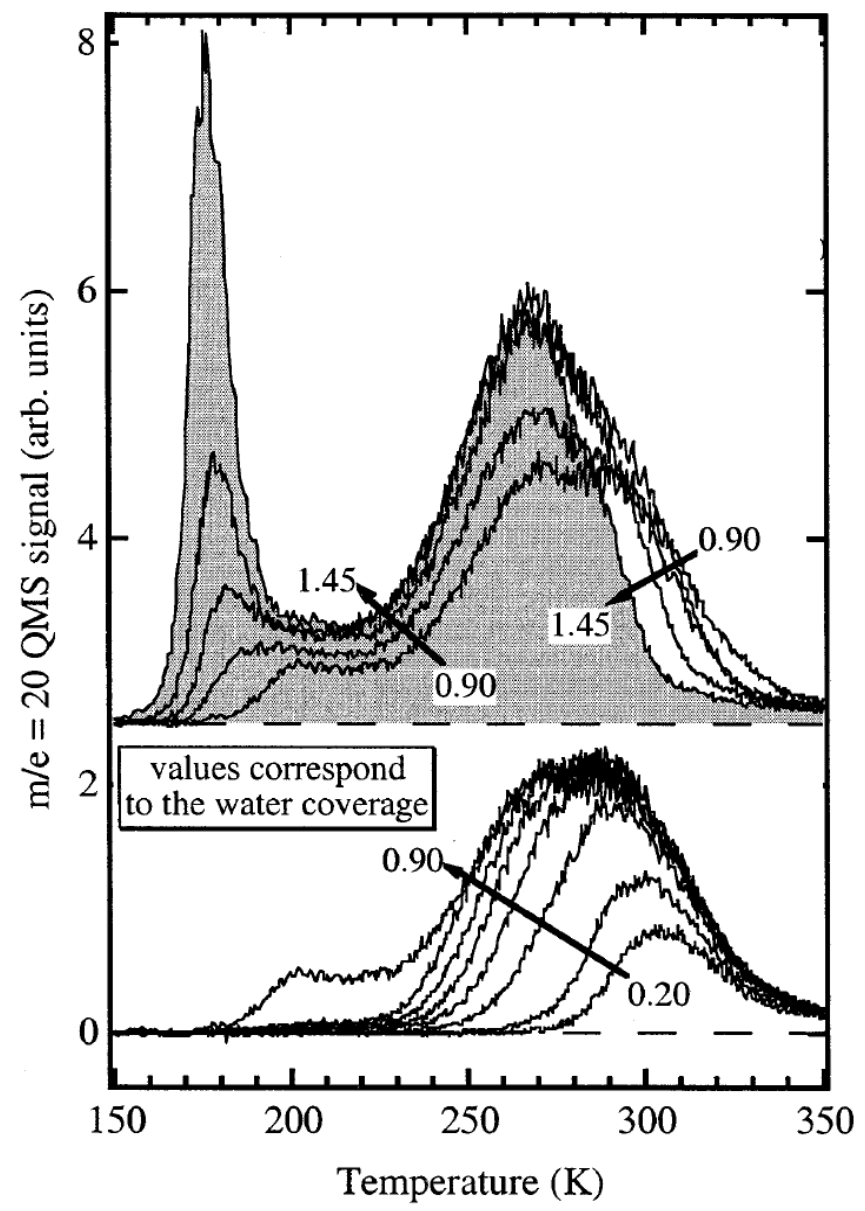

Figure 1: $\mathrm{D}_{2} \mathrm{O}$ TPD spectra $(\mathrm{m} / \mathrm{e}=20)$ from varying precoverages of $\mathrm{D}_{2} \mathrm{O}$ on a $\mathrm{TiO}_{2}(110)$ surface. The lower portion is for sub-monolayer precoverages of $\mathrm{D}_{2} \mathrm{O}$, whereas the upper portion is for precoverages above 1 monolayer. Adapted with permission from ref. 24. Copyright (2003) American Chemical Society.

Figure 2a shows a snapshot of the $\mathrm{H}_{2} \mathrm{O}(l) / \mathrm{TiO}_{2}(110)$ interface from an AIMD simulation; ${ }^{26}$ the water molecules in the first monolayer are emphasized with increased atomic radii. The water molecules in the first monolayer adsorb strongly at 5-fold coordinated $\mathrm{Ti}$ sites on the rutile $\mathrm{TiO}_{2}(110)$ surface, which corresponds to the high-temperature portion of the TPD spectra in Figure 1. The 
water molecules further away from the surface do not form direct bonds to the surface other than hydrogen bonds to the protruding 2-fold coordinated $\mathrm{O}$ atoms, and they correspond to the low-temperature portion of the TPD spectra in Figure 1. The results shown in Figure $2 \mathrm{~b}$ are based on two AIMD simulations with a time span of 14 picoseconds each (i.e., two similar simulations with different starting geometry). The adsorbed water molecules do not leave the surface within the time span of the two AIMD simulations, which results in a narrow water density peak situated $2 \AA$ above the surface when the average water density is plotted as a function of height (Figure $2 \mathrm{~b}$ ). Figure $2 \mathrm{~b}$ also shows a second water layer peak at $4 \AA$, and that the average water density approaches that of bulk liquid water (dashed line) at $6 \AA$ until the water density falls off at the water-vacuum interface at around $\sim 14 \AA$. Another AIMD study of $\mathrm{H}_{2} \mathrm{O}(l) / \mathrm{TiO}_{2}(110)$ interface has been reported, ${ }^{11}$ and a similar water density profile is observed except for a much less pronounced second layer peak.

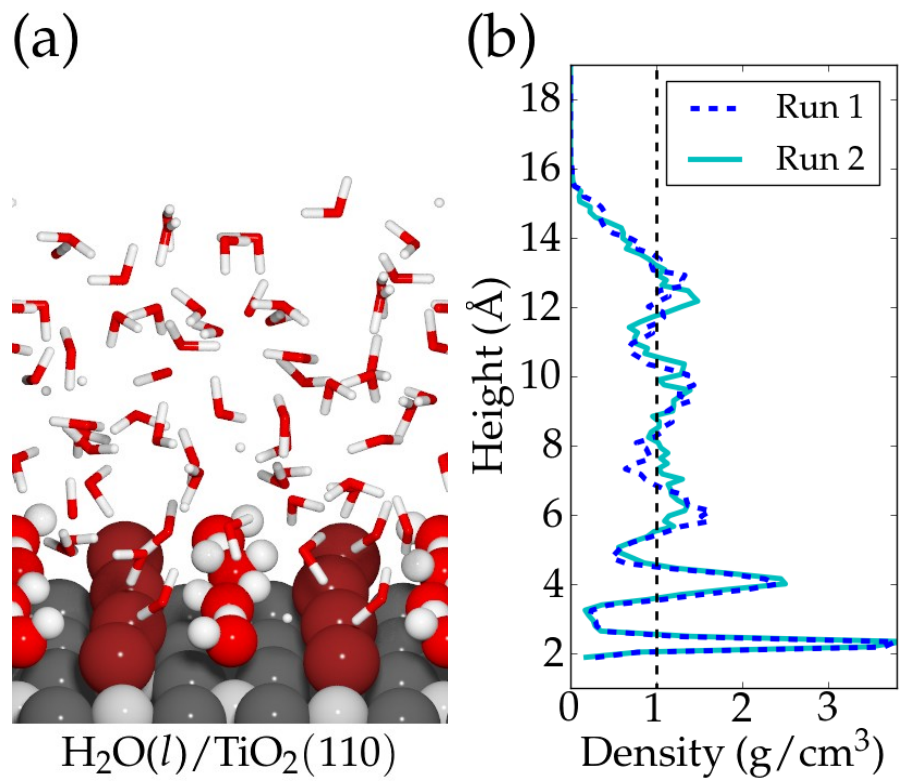

Figure 2: (a) Snapshot of the $\mathrm{H}_{2} \mathrm{O}(l) / \mathrm{TiO}_{2}(110)$ interface at $350 \mathrm{~K}$. Water molecules adsorbed on 5-fold coordinated Ti sites have increased radii. (b) Water density as a function of height above the 5-fold coordinated Ti atoms in the surface. The density from two separate AIMD runs are shown. Adapted with permission from ref. 26. Copyright (2015) American Chemical Society. 
In addition to the $\mathrm{H}_{2} \mathrm{O}(\mathrm{l}) / \mathrm{TiO}_{2}(110)$ interface, Kristoffersen and coworkers also compared the adsorption of $\mathrm{HCl}$ and catechol on the rutile $\mathrm{TiO}_{2}(110)$ surface with and without the presence of liquid water. ${ }^{26}$ The case without any water molecules represents adsorption under ultra-high vacuum (UHV) conditions. The results from DFT and AIMD simulations are shown in Figure 3. In $\mathrm{UHV}$, the $\mathrm{HCl}$ molecule adsorbs dissociatively; $\mathrm{Cl}$ adsorbs on to a 5-fold coordinated $\mathrm{Ti}$ site on the surface while $\mathrm{H}$ adsorbs to one of the protruding 2-fold coordinated $\mathrm{O}$ atoms as shown in Figure 3a. The adsorption energy of $\mathrm{HCl}$ molecule is $-1.36 \mathrm{eV}$, and its adsorption strength is higher than that of a single water molecule, which adsorbs on to a 5-fold coordinated Ti site and has the adsorption energy of $-1.11 \mathrm{eV}$. In the presence of liquid water, the $\mathrm{HCl}$ molecule adsorbs similarly to the UHV case (see Figure $3 \mathrm{~b}$ ), but the adsorption energy is reduced to $-0.6 \mathrm{eV}$. The reduction in the adsorption energy can be explained by competitive adsorption where the adsorption of $\mathrm{HCl}$ molecule accompanies a displacement of one water molecule previously adsorbed on to a 5-fold coordinated Ti site into the bulk water region, which weakens the adsorption energy. A similar phenomenon is observed for the adsorption of a catechol molecule. The adsorption energy of catechol molecule is $-2.25 \mathrm{eV}$ under UHV condition (Figure 3c), but it is reduced to $-0.8 \mathrm{eV}$ in the presence of liquid water (Figure $3 \mathrm{~d}$ ). The reduction in the adsorption energy for catechol molecule is roughly twice that of the $\mathrm{HCl}$ molecule, and such a difference aligns with the fact that the larger catechol molecule displaces two water molecules from the surface, which accompanies a higher energy cost.
(a) $\mathrm{HCl}$ at
(b) $\mathrm{HCl}$ at
(c) Catechol at
(d) Catechol at
$\mathrm{UHV} / \mathrm{TiO}_{2}(110)$
$\mathrm{H}_{2} \mathrm{O}(l) / \mathrm{TiO}_{2}(110)$
$\mathrm{UHV} / \mathrm{TiO}_{2}(110)$
$\mathrm{H}_{2} \mathrm{O}(l) / \mathrm{TiO}_{2}(110)$
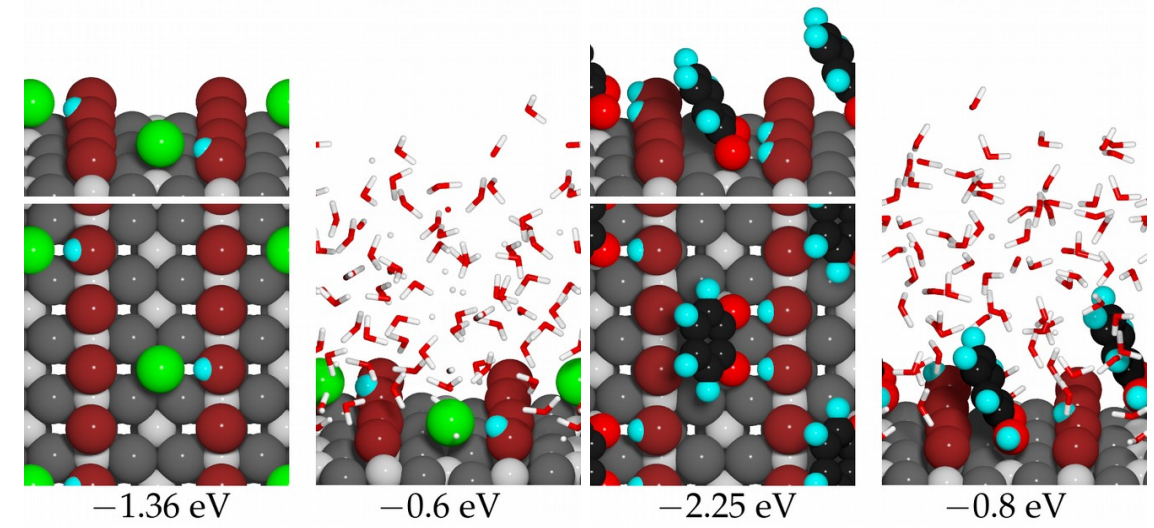

Figure 3: $\mathrm{HCl}$ adsorption at (a) the $\mathrm{TiO}_{2}(110)$ surface under UHV conditions and at (b) the $\mathrm{H}_{2} \mathrm{O}(\mathrm{l}) / \mathrm{TiO}_{2}(110)$ interface. Catechol adsorption at (c) the 
$\mathrm{TiO}_{2}(110)$ surface under UHV conditions and at (d) the $\mathrm{H}_{2} \mathrm{O}(l) / \mathrm{TiO}_{2}(110)$ interface. The destabilization of the adsorption energies between (a) and (b) and between (c) and (d) is due to competitive adsorption, where adsorption of $\mathrm{HCl}$ requires displacement of one $\mathrm{H}_{2} \mathrm{O}$ molecule and adsorption of catechol requires the displacement of two $\mathrm{H}_{2} \mathrm{O}$ molecules from the $\mathrm{H}_{2} \mathrm{O}(\mathrm{l}) / \mathrm{TiO}_{2}(110)$ interface. Adapted with permission from ref. 26. Copyright (2015) American Chemical Society.

Calculating the adsorption energy in the presence of a liquid water film using AIMD simulations as shown in Figure 3 is very time-consuming because it requires MD trajectories of sufficient time duration to capture the dynamics of liquid water. The method of calculating the adsorption energy of $\mathrm{HCl}$ using AIMD is illustrated in Scheme 1a. It would be desirable to estimate the effect of a liquid water film without AIMD simulations. Leveraging the concept of competitive adsorption, the adsorption process of a molecule (e.g., $\mathrm{HCl}$ ) on to a surface covered by strongly adsorbed $\mathrm{H}_{2} \mathrm{O}$ molecules can be broken down into three components as illustrated in Scheme $1 \mathrm{~b}:{ }^{26}$

(i) One or more adsorbed $\mathrm{H}_{2} \mathrm{O}$ molecules are displaced from the surface to allow room for the adsorbate to reach the surface. The energy cost of displacing one water molecule is estimated to be the desorption energy $\left(E_{\text {desorption }}=-E_{\text {adsorption }}\right)$ of a water molecule under UHV conditions $(+1.11$ eV per $\mathrm{H}_{2} \mathrm{O}$ on $\mathrm{TiO}_{2}(110)$ ). The desorbed $\mathrm{H}_{2} \mathrm{O}$ molecules move into the gas phase.

(ii) The displaced $\mathrm{H}_{2} \mathrm{O}(\mathrm{g})$ molecules get solvated by the liquid water film. The solvation energy of a water molecule is estimated with the experimental water condensation energy of $-0.4 \mathrm{eV}$ per $\mathrm{H}_{2} \mathrm{O}^{27}$

(iii) The adsorbate moves from the gas phase to the liquid water-solid interface and adsorbs. The energy gain is estimated by the adsorption energy under UHV conditions ( $-1.4 \mathrm{eV}$ for $\mathrm{HCl})$.

The adsorption energy of $\mathrm{HCl}$ and catechol at the $\mathrm{H}_{2} \mathrm{O}(l) / \mathrm{TiO}_{2}(110)$ interface is estimated by adding the three components. $\mathrm{HCl}$ displaces one water molecule such that the estimated adsorption energy is $-0.7 \mathrm{eV}$, whereas catechol displaces two water molecules which result in estimated adsorption energy of $-0.9 \mathrm{eV}$. These estimates are very close to the $-0.6 \mathrm{eV}$ and $-0.8 \mathrm{eV}$ obtained with AIMD simulations for $\mathrm{HCl}$ and catechol, respectively. 
(a)

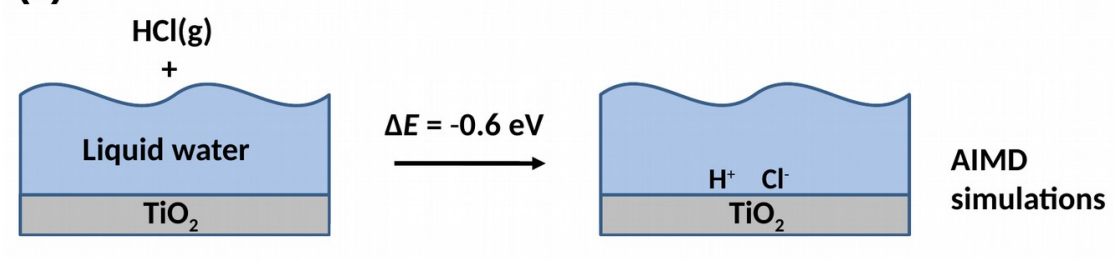

(b)

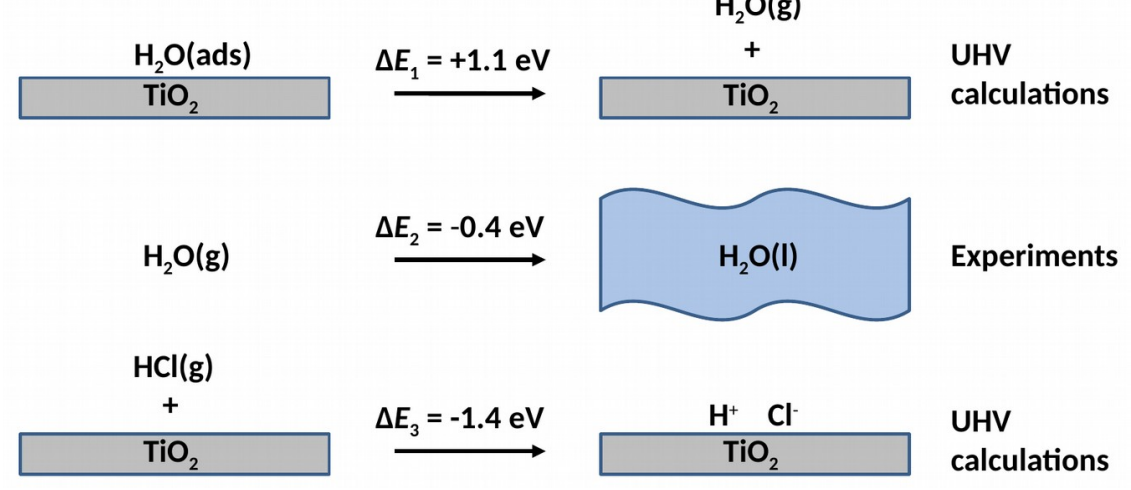

Scheme 1: (a) Illustration of the $\mathrm{HCl}$ adsorption reaction at the $\mathrm{H}_{2} \mathrm{O}(\mathrm{l}) / \mathrm{TiO}_{2}$ interface. The reaction is modeled with AIMD and has an adsorption energy of $\Delta E=-0.6 \mathrm{eV}$. (b) Illustration of $\mathrm{H}_{2} \mathrm{O}$ desorption under UHV conditions, $\mathrm{H}_{2} \mathrm{O}(\mathrm{g})$ condensation (the condensation energy is known from experiments), and $\mathrm{HCl}$ adsorption under UHV conditions. The three reactions of (b) constitute a good approximation for the full reaction of (a), i.e. $\Delta E \approx \Delta E_{1}+\Delta E_{2}+\Delta E_{3}$.

\section{Competitive adsorption at water-metal interfaces}

Competitive adsorption between water molecules and adsorbates is significantly less pronounced on $\mathrm{Pt}$ and $\mathrm{Cu}$ surfaces than on the hydrophilic $\mathrm{TiO}_{2}(110)$ surface due to weak water adsorption strength. ${ }^{28-30}$ An additional reason for the less pronounced competitive adsorption phenomenon is low water coverage of the surface metal sites. ${ }^{14,31}$ In other words, displacing water molecules from the $\mathrm{Pt}$ and $\mathrm{Cu}$ surfaces have low energy costs, and adsorbates can gain access to the surfaces without displacing many water molecules. The weak water adsorption is observed in TPD experiments for water on Pt(111), which shows that the submonolayer peak is situated at only $\sim 10 \mathrm{~K}$ higher than the multilayer peak. ${ }^{32}$ The $\mathrm{Cu}(111)$ surface is even more hydrophobic than $\mathrm{Pt}(111)$, and there is no separate 
sub-monolayer peak in the TPD spectra. Instead, the desorption peak gradually shifts to higher temperatures with increasing coverage. ${ }^{33}$

The low water coverage of the $\operatorname{Pt}(111)$ surface is confirmed in an AIMD study of the $\mathrm{H}_{2} \mathrm{O}(\mathrm{l}) / \mathrm{Pt}(111)$ interface. ${ }^{34}$ Figure 4a shows the last configuration in the AIMD trajectory where only two water molecules are adsorbed on the surface consisting of $12 \mathrm{Pt}$ atoms; the two water molecules at the surface are emphasized with increased radii. Over the full AIMD simulation 0.16 monolayer (ML) of water molecules are adsorbed on average (1 ML is one $\mathrm{H}_{2} \mathrm{O}$ * per Pt atom in the surface). The adsorbed $\mathrm{H}_{2} \mathrm{O}$ * molecules stay relatively rigidly on the surface, giving rise to an $\mathrm{O}$ atom density peak at the height of 2.3 $\AA$ above the Pt(111) surface as shown in Figure 4b. The $\mathrm{O}$ atom density peak of the second layer is at $3.2 \AA$ above the surface and has 0.59 ML water coverage.

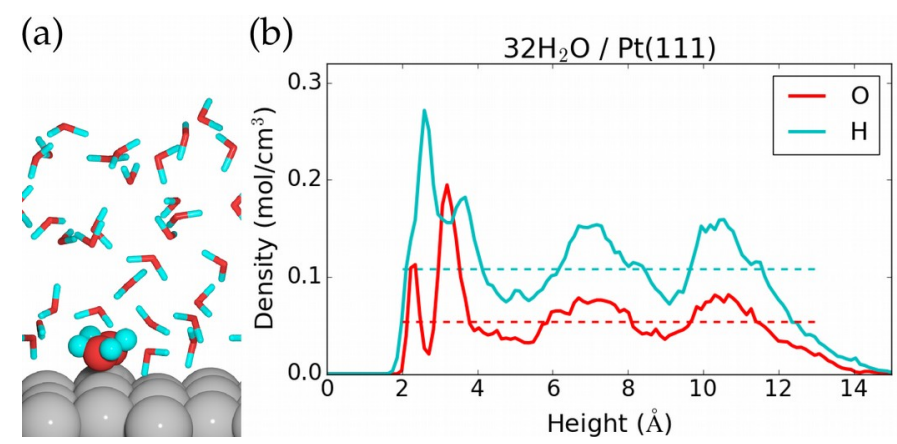

Figure 4: (a) Snapshot of the $\mathrm{H}_{2} \mathrm{O}(\mathrm{l}) / \mathrm{Pt}(111)$ interface. The two water molecules adsorbed on the surface at this particular time in the AIMD simulation are highlighted with increased radii. (b) Average atomic density as a function of height above the $\operatorname{Pt}(111)$ surface. Dashed lines show the $\mathrm{O}$ and $\mathrm{H}$ atomic densities in bulk liquid water. Reproduced with permission from ref. 34 . Copyright (2018) The Royal Society of Chemistry.

Bagger and co-workers ${ }^{35}$ have studied OCCO* adsorption at $\mathrm{H}_{2} \mathrm{O}(\mathrm{l}) / \mathrm{Cu}$ interfaces (OCCO* designates two $\mathrm{CO}$ molecules bonded together by a C-C bond and adsorbed on the surface). The adsorption energy of OCCO* was decomposed into three parts: (i) the energy cost of separating the liquid water and $\mathrm{Cu}$ surface (related to the strength of competitive adsorption), (ii) the energy gain of adsorbing OCCO* on the bare $\mathrm{Cu}$ surface and (iii) the energy gain of solvating the combined $\mathrm{OCCO}^{*}$-Cu surface with liquid water. The competitive adsorption effect is weak, and the solvation of the OCCO*-Cu surfaces by liquid water is the dominating component. The OCCO* species is, 
therefore, more stable at the $\mathrm{H}_{2} \mathrm{O}(\mathrm{l}) / \mathrm{Cu}$ interfaces than on the $\mathrm{Cu}$ surfaces under UHV conditions.

Competitive adsorption between adsorbed hydrogen and water molecules has been proposed to play a role in the electrochemical hydrogen oxidation/evolution reactions on metal surfaces. ${ }^{36}$ Indeed, some indications of competitive adsorption have been observed when hydrogen is adsorbed at the $\mathrm{H}_{2} \mathrm{O}(\mathrm{l}) / \mathrm{Pt}(111)$ interface. ${ }^{34}$ Water molecules adsorb stronger to the $\mathrm{Pt}(111)$ surface than to the $\mathrm{Cu}(111)$ surface, and the adsorbed $\mathrm{H}^{*}$ is less solvated than OCCO*. Therefore, the competitive adsorption is expected to be more pronounced in the $\mathrm{H}_{2} \mathrm{O}(l) / \mathrm{Pt}(111)$ system. The study ${ }^{34}$ found that hydrogen adsorption accompanies some water displacement from the surface. The $\operatorname{Pt}(111)$ surface in contact with liquid water has $0.16 \mathrm{ML}$ coverage. The $\mathrm{H}_{2} \mathrm{O}^{*}$ coverage is reduced to $0.15 \mathrm{ML}$ when the surface is covered by $0.08 \mathrm{ML}$ of $\mathrm{H}^{*}$ (Figure 5a) and to $0.13 \mathrm{ML}$ when the surface is covered by $0.33 \mathrm{ML} \mathrm{H}^{*}$ (Figure 5b). It is noted that $\mathrm{H}^{*}$ displaces $\mathrm{H}_{2} \mathrm{O}^{*}$ even though the combined coverage of $\mathrm{H}^{*}$ and $\mathrm{H}_{2} \mathrm{O}^{*}$ is much lower than $1 \mathrm{ML}$. Water displacement from the surface can be seen as a depletion of the $\mathrm{O}$ density peak at $2.3 \AA$ from the surface (from Figure 4 and Figure 5a to Figure 5b). The presence of liquid water has an unorthodox effect on the stability of the $\mathrm{H}^{*}$ species in the AIMD study. The $\mathrm{H}^{*}$ adsorption energies are stabilized with increasing $\mathrm{H}^{*}$ coverage at the $\mathrm{H}_{2} \mathrm{O}(l) / \mathrm{Pt}(111)$ interface $\left(-0.09 \mathrm{eV}\right.$ per $\mathrm{H}^{*}$ at $0.08 \mathrm{ML} \mathrm{H}^{*}$ and $-0.36 \mathrm{eV}$ per $\mathrm{H}^{*}$ at $0.33 \mathrm{ML}$ of $\left.\mathrm{H}^{*}\right)$. The adsorption of $\mathrm{H}^{*}$ on a bare $\mathrm{Pt}(111)$ surface is $-0.55 \mathrm{eV}$ per $\mathrm{H}^{*}$ at similar $\mathrm{H}^{*}$ coverages. One possible explanation for the observed behavior in the presence of liquid water is that the $\mathrm{H}^{*}$ and $\mathrm{H}_{2} \mathrm{O}^{*}$ species strongly repel each other (competitive adsorption), but the penalty to add more $\mathrm{H}^{*}$ species is lowered when some $\mathrm{H}^{*}$ species are already present on the surface. 


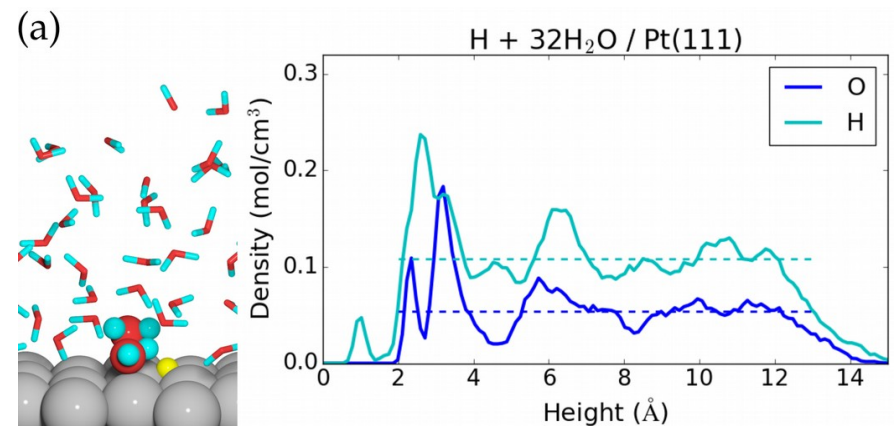

(b)

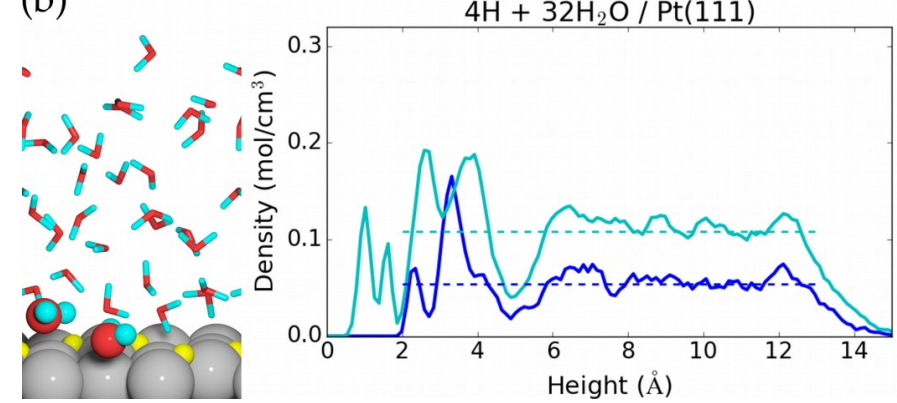

(c)

$6 \mathrm{H}+32 \mathrm{H}_{2} \mathrm{O} / \mathrm{Pt}(111)$

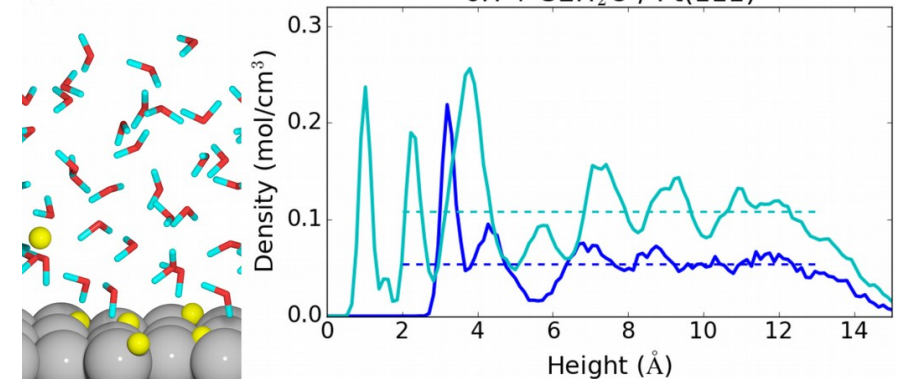

Figure 5: Side view (snapshot) of the $\mathrm{H}_{2} \mathrm{O}(\mathrm{l}) / \mathrm{Pt}(111)$ interface and average atomic density as a function of height above the $\mathrm{Pt}(111)$ surface for (a) one $\mathrm{H}^{*}$, (b) four $\mathrm{H}^{*}$, and (c) $5 \mathrm{H}^{*}+\mathrm{H}^{+}(\mathrm{aq})+\mathrm{e}^{-}$. Surface bound species are depicted with increased radii, and $\mathrm{H}^{*}$ and $\mathrm{H}^{+}$are colored yellow. Reproduced with permission from ref. 34. Copyright (2018) The Royal Society of Chemistry.

Another interesting observation in the hydrogen adsorption study is that increasing the $\mathrm{H}^{*}$ coverage to $0.50 \mathrm{ML}$ leads to the desorption of one $\mathrm{H}$ into the liquid water film as $\mathrm{H}^{+}$, which leaves one electron $\left(\mathrm{e}^{-}\right)$in the Pt slab (Figure 
5c). The electric field between the $\mathrm{H}^{+}$ion in the water film and the electron in the $\operatorname{Pt}(111)$ surface causes the water molecules at the surface to desorb and reorient ( $\mathrm{H}$ atom in $\mathrm{H}_{2} \mathrm{O}$ points towards the surface). ${ }^{37}$ The O peak at $2.3 \AA$ from the surface is completely gone in the $\mathrm{O}$ atomic density plot when the interface contains $\mathrm{H}^{+}(\mathrm{aq})$ and $\mathrm{e}^{-}$(Figure $5 \mathrm{c}$ ). No sign of steric interference is observed between the desorbed water molecules and the adsorbed $\mathrm{H}^{*}$ species (which do not protrude much from the surface). Therefore, it is plausible that the desorption of $\mathrm{H}^{*}$ species lowers the total competitive adsorption effects.

While it can be inferred from the results in Figure 5 that there is a correlation between the hydrogen adsorption process and electrostatic potential, their relationship was not explicitly investigated. Cheng and co-workers ${ }^{38}$ studied the relationship between hydrogen adsorption, water coverage, and electrostatic potential in much more detail. They used AIMD to model the $\mathrm{H}_{2} \mathrm{O}(I) / \mathrm{Pt}(100)$ interface and directly observed that gradually lowering the electrostatic potential on the standard hydrogen electrode (SHE) scale causes $\mathrm{H}_{2} \mathrm{O} *$ to desorb and stabilizes the hydrogen adsorption. These AIMD results explain experimental observations where the energy of the hydrogen adsorption depends on the potential versus SHE. ${ }^{39}$

Rossmeisl and co-workers ${ }^{13}$ have reported a strong influence of the applied electric field on the adsorption energy of a single water layer on $\operatorname{Pt}(111)$ as shown in Figure 6a. Their results further indicate that the competitive adsorption may be sensitive to the electrostatic potential, U. Figure 6a shows that the water configuration with $\mathrm{H}$ pointing away from the surface is more stable than the $\mathrm{H}$ pointing towards the surface at high electrostatic potentials (negative fields), and vice versa. The water layer in its most stable configuration for a given direction of the applied electric field is stabilized almost linearly with respect to the magnitude of the electric field. Without any applied field the two water configurations are roughly equally stable and weakly adsorbed to the surface. 

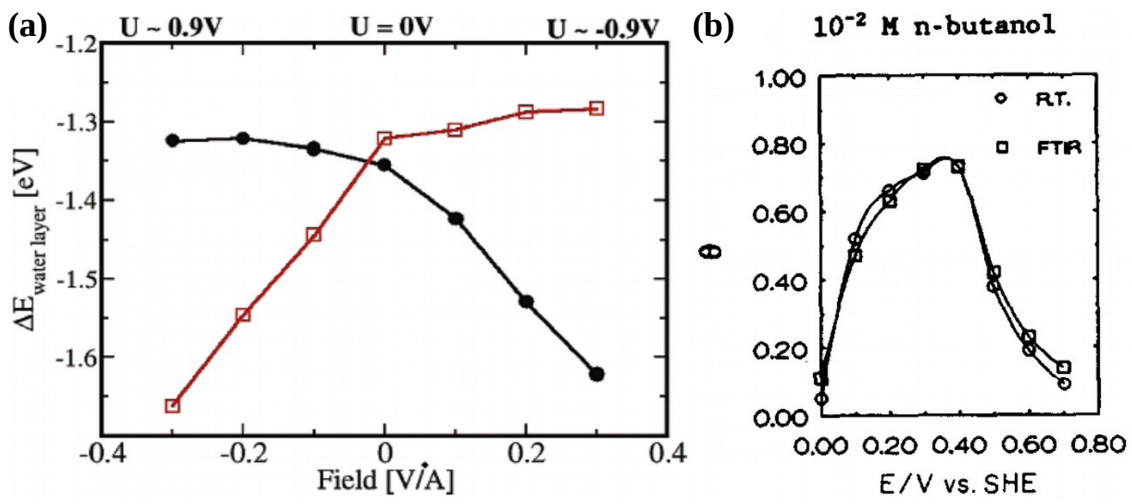

Figure 6: (a) The adsorption enthalpy ( $\Delta \mathrm{E}_{\text {water layer }}$ ) of a water layer (four water molecules) in two different orientations as a function of the applied field (lower $x$-axis) and estimated electrostatic potential (upper $x$-axis). Red is the water with hydrogen pointing up away from the metal surface and black is the water with hydrogen pointing toward the surface. Reproduced with permission from ref. 15. Copyright (2006) American Chemical Society. (b) Coverage $(\theta)$ vs. potential (E) plot for n-butanol adsorption on platinum electrodes as measured with radiotracer (RT) and FTIR spectroscopy. Reproduced with permission from ref. 18. Copyright (1992) Elsevier.

To best of our knowledge, hydrogen adsorption is the only system in which the competitive adsorption has been studied as a function of electrostatic potential. However, the adsorption of organic compounds on Pt electrodes has an interesting relationship between the surface coverage of organic species and the electrostatic potential as reported in the experimental study by Bockris and Jeng. ${ }^{18}$ The study found that for a range of organic species, the surface coverage plot with respect to potential, in general, has a bell-shaped curve with its maximum close to the potential of zero charge (pzc) (0.35 V vs. SHE) as shown in Figure 6b. The results are consistent with our understanding of competitive adsorption at water-metal interfaces: large organic species displace several water molecules from the surface, and the cost of the displacement increases at both lower and higher electrostatic potentials because the applied electric field stabilizes the water molecules at the surface. In fact, Bockris and Jeng proposed an adsorption model to explain their results, and it includes the interactions between the electric field and water dipoles as well as the displacement of water molecules from the surface when the organic molecules adsorb.

In the latest experimental study by Wuttig and co-workers, the CO coverage on an Au electrode was investigated as a function of potential using in 
situ infrared spectroelectrochemistry. ${ }^{40}$ It was found that CO molecules are adsorbed on top of Au atoms in a narrow potential window. The displacement of the CO molecules at lower electrostatic potentials directly correlates with the increased presence of the interfacial water molecules observed by the infrared signal. Therefore, it is likely that the adsorption of CO molecules at the $\mathrm{H}_{2} \mathrm{O}(l) /$ $\mathrm{Au}$ interface is also subject to potential-dependent competitive adsorption.

\section{Summary and Outlook}

Current efforts in the computational science community to model interfaces of higher complexity makes it more crucial to gain a detailed understanding of the chemical effects occurring at the interfaces. In this chapter, we have discussed such an effect relevant to the interfaces between aqueous electrolyte and solid a competitive adsorption between non-water adsorbates and water molecules. The basic concept of competitive adsorption is that the water molecules adsorb on the surface and block the access of the non-water molecules to the surface. The adsorption of non-water molecules entails a displacement of some water molecules that are already adsorbed to the surface, and the overall energy cost of the adsorption of non-water molecules due to the presence of liquid water is referred to as the strength of competitive adsorption. The factors that determine the strength of competitive adsorption is (i) the adsorption strength of the water molecules compared to bulk liquid water, (ii) the water coverage of the surface, and (iii) the number of surface sites to which the non-water adsorbate binds. The latter two describe how many water molecules are displaced upon adsorption of the non-water adsorbate while the first describes the energy cost of the displacement.

The rutile $\mathrm{TiO}_{2}(110)$ surface is very hydrophilic, and competitive adsorption is strong at the $\mathrm{H}_{2} \mathrm{O}(\mathrm{l}) / \mathrm{TiO}_{2}(110)$ interface. Water molecules adsorb to all of the 5-fold coordinated Ti sites on the surface. Therefore, non-water adsorbates that also bind to 5-fold coordinated $\mathrm{Ti}$ sites must displace the adsorbed water molecules to access the surface. The competitive adsorption is due to the energy cost of displacing those water molecules, and the geometry optimized DFT calculations can be used to estimate the results of the lengthy AIMD simulations.

The $\mathrm{Cu}$ and $\mathrm{Pt}$ metal surfaces are hydrophobic, and competitive adsorption is subtle at the $\mathrm{H}_{2} \mathrm{O}(l) / \mathrm{Cu}$ and $\mathrm{H}_{2} \mathrm{O}(l) / \mathrm{Pt}$ interfaces. However, computational models suggest that the water adsorption energy depends on the electrostatic potential of the metal surfaces, which means that it is likely that the competitive adsorption between water molecules and non-water adsorbates are also potential-dependent. Therefore, competitive adsorption has a direct influence on electrochemistry and must be understood in detail. It is crucial to 
include the competitive adsorption in computational modeling in order to describe electrochemical reactions correctly. How best to model competitive adsorption in relation to electrochemistry is an interesting topic for future computational research.

AIMD simulations have only recently been used for studying electrochemical reactions. However, AIMD simulations will likely be much more widespread in the future as the computational cost of the AIMD approach will become more tractable due to the development of more efficient algorithms/ codes as well as more powerful hardware. Therefore, we believe that additional AIMD studies on electrolyte-solid interfaces will provide a more detailed understanding of competitive adsorption effects in a broader range of systems.

\section{Acknowledgments}

Financial support was provided by V-Sustain: The VILLUM Centre for the Science of Sustainable Fuels and Chemicals (\#9455) from VILLUM FONDEN.

\section{References}

(1) Bagotzky, V. S.; Vassilyev, Y. B.; Weber, J.; Pirtskhalava, J. N. Adsorption of Anions on Smooth Platinum Electrodes. J. Electroanal. Chem. Interfacial Electrochem. 1970, 27, 31-46.

(2) Holst-Olesen, K.; Reda, M.; Hansen, H. A.; Vegge, T.; Arenz, M. Enhanced Oxygen Reduction Activity by Selective Anion Adsorption on Non-Precious Metal Catalysts. ACS Catal. 2018, 8, 7104-7112.

(3) Bligaard, T.; Nørskov, J. K.; Dahl, S.; Matthiesen, J.; Christensen, C. H.; Sehested, J. The Brønsted-Evans-Polanyi Relation and the Volcano Curve in Heterogeneous Catalysis. J. Catal. 2004, 224, 206-217.

(4) Stamenkovic, V.; Mun, B. S.; Mayrhofer, K. J. J.; Ross, P. N.; Markovic, N. M.; Rossmeisl, J.; Greeley, J.; Nørskov, J. K. Changing the Activity of Electrocatalysts for Oxygen Reduction by Tuning the Surface Electronic Structure. Angew. Chemie 2006, 118, 2963-2967.

(5) Jones, G.; Jakobsen, J. G.; Shim, S. S.; Kleis, J.; Andersson, M. P.; Rossmeisl, J.; Abild-Pedersen, F.; Bligaard, T.; Helveg, S.; Hinnemann, B.; Rostrup-Nielsen, J. R.; Chorkendorff, I.; Sehested, J; Nørskov, J. K. First Principles Calculations and Experimental Insight into Methane Steam Reforming over Transition Metal Catalysts. J. Catal. 2008, 259, 147-160. 
(6) Hodgson, A.; Haq, S. Water Adsorption and the Wetting of Metal Surfaces. Surf. Sci. Rep. 2009, 64, 381-451.

(7) Björneholm, O.; Hansen, M. H.; Hodgson, A.; Liu, L.-M.; Limmer, D. T.; Michaelides, A.; Pedevilla, P.; Rossmeisl, J.; Shen, H.; Tocci, G.; Tyrode, E.; Walz, M.; Werner, J; Bluhm, H. Water at Interfaces. Chem. Rev. 2016, 116, 7698-7726.

(8) Carrasco, J.; Hodgson, A.; Michaelides, A. A Molecular Perspective of Water at Metal Interfaces. Nat. Mater. 2012, 11, 667.

(9) Magnussen, O. M.; Groß, A. Toward an Atomic-Scale Understanding of Electrochemical Interface Structure and Dynamics. J. Am. Chem. Soc. 2019, 141, 4777-4790.

(10) Gauthier, J. A.; Ringe, S.; Dickens, C. F.; Garza, A. J.; Bell, A. T.; Head-Gordon, M.; Nørskov, J. K.; Chan, K. Challenges in Modeling Electrochemical Reaction Energetics with Polarizable Continuum Models. ACS Catal. 2019, 9, 920-931.

(11) Liu, L.-M.; Zhang, C.; Thornton, G.; Michaelides, A. Structure and Dynamics of Liquid Water on Rutile $\mathrm{TiO}_{2}(110)$. Phys. Rev. B 2010, 82, 161415.

(12) Calegari Andrade, M. F.; Ko, H.-Y.; Car, R.; Selloni, A. Structure, Polarization, and Sum Frequency Generation Spectrum of Interfacial Water on Anatase $\mathrm{TiO}_{2}$. J. Phys. Chem. Lett. 2018, 9, 6716-6721.

(13) Sakong, S.; Forster-Tonigold, K.; Groß, A. The Structure of Water at a Pt(111) Electrode and the Potential of Zero Charge Studied from First Principles. J. Chem. Phys. 2016, 144, 194701.

(14) Le, J.; Iannuzzi, M.; Cuesta, A.; Cheng, J. Determining Potentials of Zero Charge of Metal Electrodes versus the Standard Hydrogen Electrode from Density-Functional-Theory-Based Molecular Dynamics. Phys. Rev. Lett. 2017, 119, 16801.

(15) Rossmeisl, J.; Nørskov, J. K.; Taylor, C. D.; Janik, M. J.; Neurock, M. Calculated Phase Diagrams for the Electrochemical Oxidation and Reduction of Water over Pt(111). J. Phys. Chem. B 2006, 110, 2183321839.

(16) Calle-Vallejo, F.; F. de Morais, R.; Illas, F.; Loffreda, D.; Sautet, P. Affordable Estimation of Solvation Contributions to the Adsorption Energies of Oxygenates on Metal Nanoparticles. J. Phys. Chem. C 2019, 123, 5578-5582. 
(17) Andanson, J.-M.; Baiker, A. Exploring Catalytic Solid/Liquid Interfaces by in Situ Attenuated Total Reflection Infrared Spectroscopy. Chem. Soc. Rev. 2010, 39, 4571-4584.

(18) Bockris, J. O’M.; Jeng, K. T. In-Situ Studies of Adsorption of Organic Compounds on Platinum Electrodes. J. Electroanal. Chem. 1992, 330, 541-581.

(19) Shen, Y. R. Surface Properties Probed by Second-Harmonic and SumFrequency Generation. Nature 1989, 337, 519-525.

(20) Wang, C.; Groenzin, H.; Shultz, M. J. Comparative Study of Acetic Acid, Methanol, and Water Adsorbed on Anatase $\mathrm{TiO}_{2}$ Probed by Sum Frequency Generation Spectroscopy. J. Am. Chem. Soc. 2005, 127, 9736-9744.

(21) Ketteler, G.; Yamamoto, S.; Bluhm, H.; Andersson, K.; Starr, D. E.; Ogletree, D. F.; Ogasawara, H.; Nilsson, A.; Salmeron, M. The Nature of Water Nucleation Sites on $\mathrm{TiO}_{2}(110)$ Surfaces Revealed by Ambient Pressure X-Ray Photoelectron Spectroscopy. J. Phys. Chem. C 2007, 111, 8278-8282.

(22) Foster, M.; D’Agostino, M.; Passno, D. Water on MgO(100)—An Infrared Study at Ambient Temperatures. Surf. Sci. 2005, 590, 31-41.

(23) Yamamoto, S.; Kendelewicz, T.; Newberg, J. T.; Ketteler, G.; Starr, D. E.; Mysak, E. R.; Andersson, K. J.; Ogasawara, H.; Bluhm, H.; Salmeron, M.; Brown Jr., G. E.; Nilsson, A. Water Adsorption on $\alpha-$ $\mathrm{Fe}_{2} \mathrm{O}_{3}(0001)$ at near Ambient Conditions. J. Phys. Chem. C 2010, 114, 2256-2266.

(24) Henderson, M. A.; Epling, W. S.; Peden, C. H. F.; Perkins, C. L. Insights into Photoexcited Electron Scavenging Processes on $\mathrm{TiO}_{2}$ Obtained from Studies of the Reaction of $\mathrm{O}_{2}$ with $\mathrm{OH}$ Groups Adsorbed at Electronic Defects on $\mathrm{TiO}_{2}(110)$. J. Phys. Chem. B 2003, 107, 534545.

(25) Imad-Uddin Ahmed, S.; Perry, S. S.; El-Bjeirami, O. Desorption and Reaction of Water on $\mathrm{MgO}(100)$ Studied as a Function of Surface Preparation. J. Phys. Chem. B 2000, 104, 3343-3348.

(26) Kristoffersen, H. H.; Shea, J.-E.; Metiu, H. Catechol and $\mathrm{HCl}$ Adsorption on $\mathrm{TiO}_{2}(110)$ in Vacuum and at the Water-TiO ${ }_{2}$ Interface. $J$. Phys. Chem. Lett. 2015, 6, 2277-2281.

(27) Wagman, D. D.; Evans, W. H.; Parker, V. B.; Schumm, R. H.; Halow, I.; Bailey, S. M.; Churney, K. L.; Nuttall, R. L. The NBS Tables of 
Chemical Thermodynamic Properties. Selected Values for Inorganic and $\mathrm{C}_{1}$ and $\mathrm{C}_{2}$ Organic Substances in SI Units. J. Phys. Chem. Ref. Data 1982, 11. Suppl. 2

(28) Michaelides, A.; Alavi, A.; King, D. A. Insight into $\mathrm{H}_{2} \mathrm{O}$-Ice Adsorption and Dissociation on Metal Surfaces from First-Principles Simulations. Phys. Rev. B 2004, 69, 113404.

(29) Tatarkhanov, M.; Ogletree, D. F.; Rose, F.; Mitsui, T.; Fomin, E.; Maier, S.; Rose, M.; Cerdá, J. I.; Salmeron, M. Metal- and HydrogenBonding Competition during Water Adsorption on $\operatorname{Pd}(111)$ and $\mathrm{Ru}(0001)$. J. Am. Chem. Soc. 2009, 131, 18425-18434.

(30) Carrasco, J.; Klimeš, J.; Michaelides, A. The Role of van Der Waals Forces in Water Adsorption on Metals. J. Chem. Phys. 2013, 138, 24708.

(31) Groß, A.; Schnur, S. Properties of Metal-Water Interfaces Studied from First Principles. New J. Phys. 2009, 11, 125003.

(32) Haq, S.; Harnett, J.; Hodgson, A. Growth of Thin Crystalline Ice Films on Pt(111). Surf. Sci. 2002, 505, 171-182.

(33) Hinch, B. J.; Dubois, L. H. Stable and Metastable Phases of Water Adsorbed on $\mathrm{Cu}(111)$. J. Chem. Phys. 1992, 96, 3262-3268.

(34) Kristoffersen, H. H.; Vegge, T.; Hansen, H. A. OH Formation and $\mathrm{H}_{2}$ Adsorption at the Liquid Water-Pt(111) Interface. Chem. Sci. 2018, 9, 6912-6921.

(35) Bagger, A.; Arnarson, L.; Hansen, M. H.; Spohr, E.; Rossmeisl, J. Electrochemical CO Reduction: A Property of the Electrochemical Interface. J. Am. Chem. Soc. 2019, 141, 1506-1514.

(36) Zheng, J.; Nash, J.; Xu, B.; Yan, Y. Perspective-Towards Establishing Apparent Hydrogen Binding Energy as the Descriptor for Hydrogen Oxidation/Evolution Reactions. J. Electrochem. Soc. 2018, 165, H27H29.

(37) Huzayyin, A.; Chang, J. H.; Lian, K.; Dawson, F. Interaction of Water Molecule with $\mathrm{Au}(111)$ and $\mathrm{Au}(110)$ Surfaces under the Influence of an External Electric Field. J. Phys. Chem. C 2014, 118, 3459-3470.

(38) Cheng, T.; Wang, L.; Merinov, B. V; Goddard, W. A. Explanation of Dramatic pH-Dependence of Hydrogen Binding on Noble Metal Electrode: Greatly Weakened Water Adsorption at High pH. J. Am. Chem. Soc. 2018, 140, 7787-7790. 
(39) Sheng, W.; Zhuang, Z.; Gao, M.; Zheng, J.; Chen, J. G.; Yan, Y. Correlating Hydrogen Oxidation and Evolution Activity on Platinum at Different $\mathrm{pH}$ with Measured Hydrogen Binding Energy. Nat. Commun. 2015, 6, 5848.

(40) Wuttig, A.; Ryu, J.; Surendranath, Y. Electrolyte Competition Controls Surface Binding of $\mathrm{CO}$ Intermediates to $\mathrm{CO}_{2}$ Reduction Catalysts. ChemRxiv 2019. Preprint. DOI: 10.26434/chemrxiv.7929038.v1 